\title{
Annealing Effects on the Structural, Optical, and UV Photoresponse Properties of ZnO Nanostructures Prepared by RF-Magnetron Sputtering at Different Deposition Temperatures
}

\author{
Husam S. Al-Salman • M. J. Abdullah
}

Received: 13 January 2014/Revised: 23 June 2014/Published online: 21 December 2014

(C) The Chinese Society for Metals and Springer-Verlag Berlin Heidelberg 2014

\begin{abstract}
Undoped $\mathrm{ZnO}$ nanostructures were deposited on $\mathrm{SiO}_{2} / \mathrm{Si}$ substrates via radio frequency magnetron sputtering at different deposition temperatures (room temperature, 200, 300, and $400{ }^{\circ} \mathrm{C}$ ). The prepared samples were annealed at $500{ }^{\circ} \mathrm{C}$ for $2 \mathrm{~h}$ under an $\mathrm{N}_{2}$ flow. The structural, surface morphological, optical, and photoresponse characteristics of $\mathrm{ZnO}$ nanostructures as deposited and after annealing were then investigated. The energy bandgaps of all samples after annealing (3.22-3.28 eV) decreased compared with those of the as-deposited specimens. The barrier height increased when the deposition temperature increased and reached $0.77 \mathrm{eV}$ at $400{ }^{\circ} \mathrm{C}$ after annealing with a leakage current of $0.17 \mu \mathrm{A}$ at a $5 \mathrm{~V}$ bias. The UV photodetector device which was deposited at the optimal temperature of $300{ }^{\circ} \mathrm{C}$, has $12.51 \times 10^{3} \%$ photosensitivity, $2.259 \mu \mathrm{A}$ dark current, $0.508 \mathrm{~s}$ response time, and $0.466 \mathrm{~s}$ recovery time. The dark current significantly decreased for all samples after annealing. The proposed UV photodetectors exhibit high performance, high photosensitivity, shorter response and recovery times, and excellent stability at lower bias voltages of 5 and $2 \mathrm{~V}$.
\end{abstract}

KEY WORDS: Undoped ZnO; UV photoresponse; Deposition temperatures; Annealing effect

\section{Introduction}

Metal-semiconductor-metal (MSM) photodetectors, Schottky photodiodes, and $\mathrm{p}-\mathrm{n}$ photodiodes are generally used as UV photodetectors. The formation of the Schottky contact is vital to achieve a large barrier height at the metal-semiconductor interface for high performance Schottky and MSM photodetectors. Thus, a small leakage current and a high breakdown voltage can improve the photocurrent $\left(I_{\mathrm{ph}}\right)$ to dark current $\left(I_{\text {dark }}\right)$ ratio, which leads to a high

Available online at http://link.springer.com/journal/40195

H. S. Al-Salman $(\bowtie) \cdot$ M. J. Abdullah

School of Physics, University Sains Malaysia, 11800 Gelugor,

Penang, Malaysia

e-mail: husam.shakir@yahoo.com

H. S. Al-Salman

Department of Physics, College of Science, University of

Basrah, Basrah, Iraq photoresponse [1-5]. Several studies have investigated the Schottky contact on $\mathrm{ZnO}$ crystals [5-9] that were fabricated using Pd, Ir, Au, and Ag as Schottky metals. Le et al. [6] investigated the effect of post annealing on a Pt/ZnO Schottky diode prepared on an $\mathrm{SiO}_{2}$ substrate by pulsed laser deposition and achieved a barrier height of $0.8 \mathrm{eV}$ with a leakage current of $1.5 \times 10^{-5} \mathrm{~A} / \mathrm{cm}^{2}$. Mtangi et al. [9] used Pd metal as a Schottky contact on $\mathrm{ZnO}$ and studied the current-voltage $(I-V)$ characteristics as a function of temperature. Owing to the versatile characteristics of $\mathrm{ZnO}$ such as its chemical sensitivity to many gases, high chemical stability, non-toxicity, low cost, radiation hardness, high optical gain, high-temperature resistance, and flexibility in fabrication $[10,11], \mathrm{ZnO}$ has been applied in piezoelectric transducers, transparent conducting oxides, UV light emitting diodes, laser diodes, gas sensors, and photodetectors [12, 13]. Efficient, high performance photodetectors should exhibit high photosensitivity and selectivity, faster response and recovery times, and reproducible characteristics [14]. High performance UV photodetectors have attracted considerable 
attention because of their applications in high technology military equipment, biological and chemical flame detection, and space communications [11, 15]. Optimization of the $\mathrm{ZnO}$ nanostructure at a certain deposition temperature $\left(T_{\mathrm{s}}\right)$ is vital for designing UV sensors. Numerous studies have been conducted on the effects of deposition temperature and post annealing on the crystalline and morphological properties of $\mathrm{ZnO}$ nanostructures [16-18]. Zhang [18] studied the effect of heat treatment on the structural and optical properties of $\mathrm{ZnO}$ films deposited on Si and quartz substrates by the sol-gel method. Elilarassi and Chandrasekaran [17] investigated the effects of annealing from 350 to $550{ }^{\circ} \mathrm{C}$ on the photoluminescence (PL) spectra and chemical compositions of $\mathrm{ZnO}$ films prepared via a modified liquid flow deposition method. Hwang et al. [19] used ambient nitrogen during annealing at different temperatures as well as studied the structural and optical characteristics of Al-doped $\mathrm{ZnO}$ nanostructures prepared on a soda-lime glass substrate by RF-magnetron sputtering. All these studies rarely discussed or addressed the effects of annealing and/or deposition temperature on the UV photoresponse properties.

To the best of our knowledge, no reports have been published on the effects of post annealing on the $\mathrm{Pd}$ Schottky contact on $\mathrm{ZnO}$ for UV photodetectors deposited at different deposition temperature. In the present study, undoped $\mathrm{ZnO}$ nanostructure-based UV photodetectors were fabricated on $\mathrm{SiO}_{2} / \mathrm{Si}(n-100)$ with comb-like Pd electrodes using RF-magnetron sputtering at different deposition temperatures. The effects of annealing at $500{ }^{\circ} \mathrm{C}$ under an $\mathrm{N}_{2}$ flow on the structural, optical, and UV photoresponse properties were investigated. Schottky properties such as barrier heights, ideality factors, and leakage current were calculated based on the thermionic emission theory. The $(I-V)$ characteristics were then determined to obtain $I_{\text {dark }}$ and $I_{\mathrm{ph}}$.

\section{Experimental}

An n-type (100) silicon wafer $(8 \mathrm{~mm} \times 8 \mathrm{~mm})$ was cleaned via the Radio Corporation of America standard method (RCA). The wafer was then heated to $1,100{ }^{\circ} \mathrm{C}$ for $5 \mathrm{~h}$ using a tube furnace to produce a thick $\mathrm{SiO}_{2}$ layer by wet air flow. Undoped $\mathrm{ZnO}$ nanostructure-based UV photodetectors were deposited by RF-magnetron sputtering at different $T_{\mathrm{s}}$ [room temperature (RT), 200, 300, and $400{ }^{\circ} \mathrm{C}$ ] using a high purity (99.99\%) $\mathrm{ZnO}$ target at a base pressure and RF power of $2 \times 10^{-3} \mathrm{~Pa}$ and $150 \mathrm{~W}$, respectively. Interdigital, comb-like $200 \mathrm{~nm}$ Pd electrodes were deposited on the $\mathrm{ZnO}$ layer surface using a metal mask through the same RF-magnetron sputtering unit (Edwards, A500). Prior to the actual deposition, the target ( $\mathrm{ZnO}$ or $\mathrm{Pd})$ was sputtered for $5 \mathrm{~min}$ to eliminate any contamination on the target surface. The width and space of the contact electrodes were 0.3 and $0.35 \mathrm{~mm}$, respectively. The samples were then annealed at $500{ }^{\circ} \mathrm{C}$ for $2 \mathrm{~h}$ under an $\mathrm{N}_{2}$ flow. Figure 1a shows a schematic of the Pd electrodes on the surface of the $\mathrm{ZnO}$ nanostructures of the UV photodetector device.

The $I-V$ characteristics of the devices in the dark and under UV light were measured under a DC voltage sweep using a Keithley 2400 high-voltage source-measure unit. The spectral responses of the devices were determined using a $200 \mathrm{~W} \mathrm{Hg}(\mathrm{Xe})$ ozone-free lamp and a monochromator with a power meter (Newport, Model 2936-c) to calibrate the output power. X-ray diffraction (XRD) measurements were performed from $2 \theta$ of $20^{\circ}-60^{\circ}$ using a PANalytical X'Pert PRO MRD PW3040 (Almelo, Netherlands) with a $\mathrm{Cu} K_{\alpha}$ radiation $(\lambda=0.1541 \mathrm{~nm})$. Field emission scanning electron microscopy (FESEM) images were obtained using a Leo-Supra 50VP (Carl Zeiss, Germany) equipped with an energy-dispersive X-ray spectroscopy (EDX) system. The RT PL spectrum of the product was used to analyze the optical properties of the detector using a Jobin Yvon HR 800 UV (Edison, NJ, USA) with a He-Cd laser operating at $325 \mathrm{~nm}$. UV-Vis measurements of the film were conducted at RT using a Shimadzu UV-Vis 1800 spectrophotometer. Atomic force microscopy (AFM, Dimension Edge, Bruker) in tapping mode and equipped with Nano-Drive Dimension-Edge Tapping image-processing software was used to measure the surface roughness.

\section{Results and Discussion}

Figure 2 shows the XRD spectra of the $\mathrm{ZnO}$ nanostructures deposited at different $T_{\mathrm{s}}$ (RT, 200, 300, and $400{ }^{\circ} \mathrm{C}$ ) by RFmagnetron sputtering before (as deposited, Fig. 2a) and after annealing at $500{ }^{\circ} \mathrm{C}$ for $2 \mathrm{~h}$ under an $\mathrm{N}_{2}$ flow (Fig. 2b). All $\mathrm{ZnO}$ samples exhibited a (002) preferred

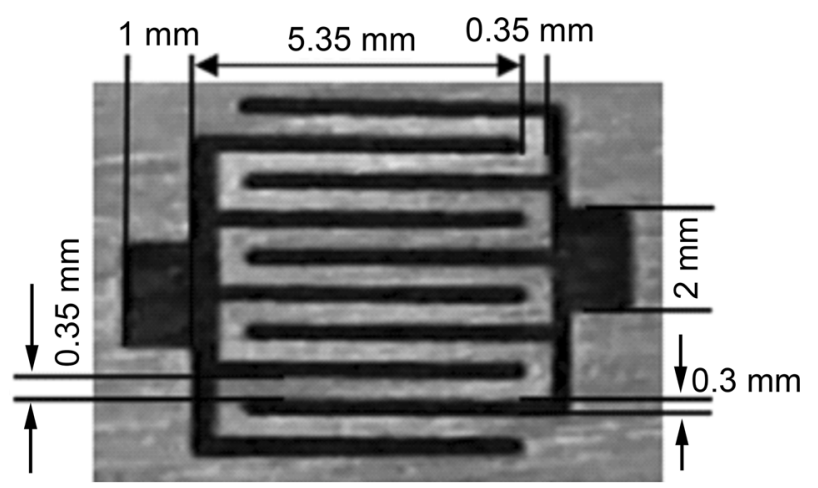

Fig. 1 Schematic structure of the $\mathrm{Pd}$ electrodes on the $\mathrm{ZnO}$ photodetector 

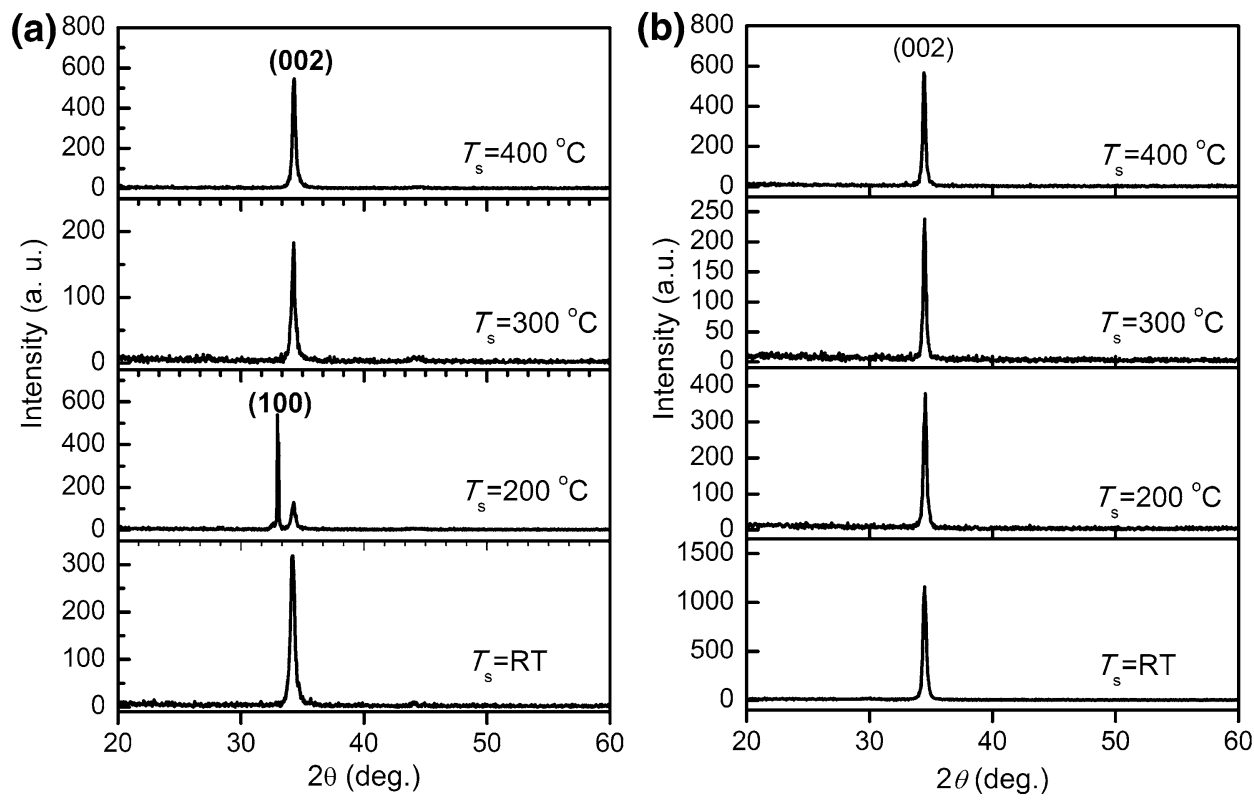

Fig. 2 XRD patterns of the $\mathrm{ZnO}$ nanostructures deposited at different substrate temperatures: $\mathbf{a}$ as deposited, $\mathbf{b}$ after annealing at $500{ }^{\circ} \mathrm{C}$ for $2 \mathrm{~h}$ under $\mathrm{N}_{2}$ flow

orientation, except for the sample deposited at $200{ }^{\circ} \mathrm{C}$, which exhibited a preferred (100) plane orientation (Fig. 2a). This peak of (100) plane of the sample deposited at $200{ }^{\circ} \mathrm{C}$ disappeared after annealing, and the preferred orientation changed to that of the (002) plane. This result is attributed to the low surface energy of the (002) plane, which induced the growth of grains along this plane rather than along the other orientation [20]. The main (002) diffraction peak was due to the $c$-axis oriented phase of the hexagonal wurtzite structure of $\mathrm{ZnO}$, which correspond to ICSD card No. 01-089-0511. The intensity of the (002) phase of all samples (except that of the sample deposited at $400{ }^{\circ} \mathrm{C}$ ) increased after annealing at $500{ }^{\circ} \mathrm{C}$, indicating that annealing improved the crystal quality. For the sample deposited at $400{ }^{\circ} \mathrm{C}$, the unchanged (002) peak intensity may be attributed to the near similarity of the annealing temperature to the $T_{\mathrm{s}}$.

The crystallite size, $D$, of the films was calculated using the Debye-Scherer equation [21-23]:

$D=\frac{0.9 \lambda}{\beta \cos \theta}$,

where $\lambda$ is the wavelength of radiation $(0.1541 \mathrm{~nm}), \beta$ is the full width at half maximum (FWHM), and $\theta$ is the Bragg angle. The lattice parameters $c$ of the films were calculated using the following formula [21]:

$\sin ^{2} \theta=\frac{\lambda^{2}}{4}\left[\frac{4}{3}\left(\frac{h^{2}+h k+k^{2}}{a^{2}}\right)+\frac{l^{2}}{c^{2}}\right]$ where $h, k$, and $l$ are Miller's indices. The strains $\left(\varepsilon_{\mathrm{zz}}\right)$ along the $c$-axis of the $\mathrm{ZnO}$ nanostructure were calculated using the following formula [24]:

$\varepsilon_{\mathrm{zz}}=\frac{c-c_{0}}{c_{0}} \times 100 \%$,

where $c_{0}$ is the standard lattice constant of the unstrained $\mathrm{ZnO}$. The calculated $c$, FWHM, $\varepsilon_{\mathrm{zz}}$, and $D$ of the $\mathrm{ZnO}$ nanostructures deposited at different $T_{\mathrm{s}}$ before and after annealing are listed in Table 1. The lattice parameter $c$ is consistent with the reported standard values for unstrained $\mathrm{ZnO}\left(c_{0}=0.5205 \mathrm{~nm}\right)$. The strain values of the asdeposited samples were high but decreased after annealing. The positive strain values indicate the occurrence of tensile strain in the $\mathrm{ZnO}$ nanostructures, whereas the negative values suggest the presence of compressive strain. The lattice parameter $c$ of all samples decreased after annealing at $500{ }^{\circ} \mathrm{C}$ (Table 1), indicating reduction in the internal stress. These results are consistent with those obtained by Hwang et al. [19], who studied the effects of annealing under an $\mathrm{N}_{2}$ flow on the crystal structure of $\mathrm{Al}$-doped $\mathrm{ZnO}$ nanostructures. The $\mathrm{ZnO}$ nanostructure deposited at $400{ }^{\circ} \mathrm{C}$ exhibited lower strain after annealing compared with the other samples. The considerably low compressive strains obtained after annealing $(-0.038$ and $-0.057 \%$ ) suggest that the synthesized $\mathrm{ZnO}$ nanostructures have high crystal qualities [24]. These values are comparable to those obtained by Hassan et al. [24] for $\mathrm{ZnO}$ nanorods prepared by microwave-assisted chemical 
Table 1 Structural properties of the $\mathrm{ZnO}$ nanostructure deposited at different temperatures before (as deposited) and after annealing at $500{ }^{\circ} \mathrm{C}$ for $2 \mathrm{~h}$ under $\mathrm{N}_{2}$ flow

\begin{tabular}{|c|c|c|c|c|c|c|c|c|c|c|}
\hline \multirow[t]{2}{*}{$T_{\mathrm{s}}\left({ }^{\circ} \mathrm{C}\right)$} & \multicolumn{5}{|c|}{ As deposited } & \multicolumn{5}{|c|}{ After annealing } \\
\hline & $2 \theta$ (deg.) & FWHM (deg.) & $D(\mathrm{~nm})$ & $c(\mathrm{~nm})$ & $\varepsilon_{\mathrm{zz}}(\%)$ & $2 \theta$ (deg.) & FWHM (deg.) & $D(\mathrm{~nm})$ & $c(\mathrm{~nm})$ & $\varepsilon_{\mathrm{zz}}(\%)$ \\
\hline RT & 34.319 & 0.412 & 19.8 & 5.223 & 0.34 & 34.453 & 0.295 & 28.26 & 5.203 & -0.038 \\
\hline 200 & 34.177 & 0.442 & 18.8 & 5.244 & 0.74 & 34.524 & 0.295 & 28.27 & 5.193 & -0.23 \\
\hline 300 & 34.264 & 0.196 & 42.2 & 5.231 & 0.49 & 34.456 & 0.196 & 42.4 & 5.202 & -0.057 \\
\hline 400 & 34.297 & 0.246 & 33.8 & 5.226 & 0.4 & 34.43 & 0.196 & 42.4 & 5.206 & 0.019 \\
\hline
\end{tabular}

bath deposition. However, after annealing, strain value (0.019) of $\mathrm{ZnO}$ deposited at $400{ }^{\circ} \mathrm{C}$ was significantly low compared with those obtained in previous studies [24-26]. Figure 3 shows the crystallite sizes of the $\mathrm{ZnO}$ nanostructures before and after annealing. The crystallite sizes of all samples increased after annealing indicate that annealing enhanced crystallization. This result is consistent with those of previous studies [17, 18]. Annealing at high temperatures and increased $T_{\mathrm{s}}$ generally lead to increased crystallite sizes. These results can be attributed to the increased mobility of adatoms and increased surface diffusion. These phenomena enable these adatoms to migrate longer distances and occupy lattice sites with favorable stable energies. In turn, the crystallite sizes enhanced because of surface energy minimization [27]. For the sample deposited at $300{ }^{\circ} \mathrm{C}$, the crystallite size of the as-deposited $\mathrm{ZnO}(42.2 \mathrm{~nm})$ slightly increased after annealing $(42.4 \mathrm{~nm})$ compared with those of other samples. Figure 4 shows the AFM images of the $\mathrm{ZnO}$ nanostructure surface before and after annealing. The surfaces of all samples were uniform. The variation in the roughness $\left(R_{\text {rms }}\right)$ as a function of $T_{\mathrm{s}}$ is shown in Fig. 5. Generally, $R_{\text {rms }}$ increased with increasing $T_{\mathrm{s}}$. All samples exhibited higher $R_{\text {rms }}$ after annealing, indicating increased

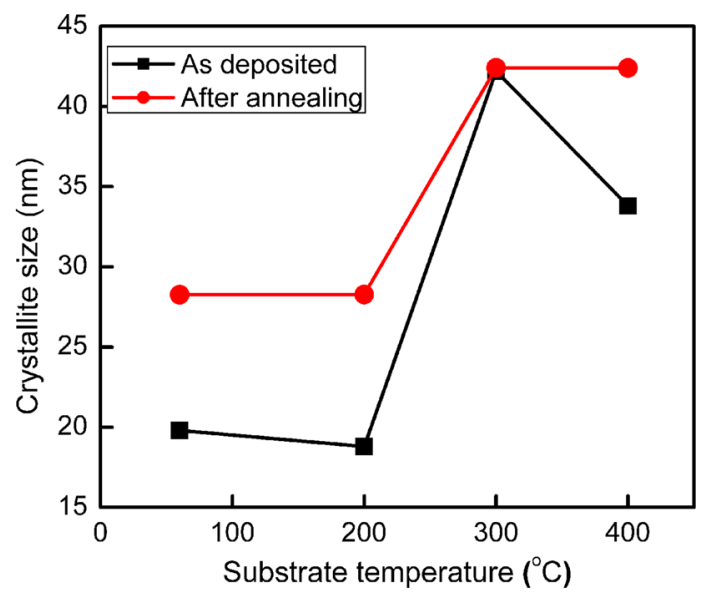

Fig. 3 Crystalline size of the $\mathrm{ZnO}$ nanostructure deposited at different substrate temperatures porosity as well as the formation of voids between the crystallite grains. The high $R_{\mathrm{rms}}$ can be attributed to the growth of the crystallite grains [28] and is consistent with the XRD findings (Fig. 3). Figure 6 shows the FESEM images of the as-deposited and annealed $\mathrm{ZnO}$ nanostructures. The polygonal nanoparticles were uniformly distributed and did not show cracks, indicating good crystalline quality. After annealing, the voids in the samples increased (Fig. 6b) compared with those in the as-deposited samples at different $T_{\mathrm{s}}$ (Fig. 6a). The increased number of voids resulted in increased porosity and may be attributed to the enhanced grain migration to the boundaries. This migration increased the aggregation of grains during the annealing processes, which resulted in the formation of voids [20]. This finding is consistent with the AFM results (Fig. 5). The abundance of small crystallite grains that were observed in the annealed $\mathrm{ZnO}$ samples deposited at 300 and $400{ }^{\circ} \mathrm{C}$ (Fig. 6b) compared with those in the as-deposited samples (Fig. 6a) may be attributed to the separation of the small grains from the larger crystallites to form new crystallite grains. Figure 7 shows the RT PL spectra of the as-deposited and annealed $\mathrm{ZnO}$ nanostructures. The PL spectra of the as-deposited samples consisted of high intensity peaks in the UV region as well as of a considerably weak broad peak located in the visible region (Fig. 7a). The UV-to-vis PL peak intensity ratios $\left(I_{\mathrm{UV}} / I_{\mathrm{VS}}\right)$ for the as-deposited $\mathrm{ZnO}$ at RT, 200, 300, and $400{ }^{\circ} \mathrm{C}$ were $17,3.7,15$, and 33 , respectively, indicating that the $\mathrm{ZnO}$ deposited at $400{ }^{\circ} \mathrm{C}$ exhibited higher crystal quality compared with the other samples. After annealing at $500{ }^{\circ} \mathrm{C}$ under an $\mathrm{N}_{2}$ flow, the PL intensity in the UV region significantly decreased whereas that in the visible region increased, which led to decreased $I_{\mathrm{UV}} / I_{\mathrm{VS}}$ ratio. The UV emission originated from the excitonic recombination that corresponds to the near-band-edge exciton emission of the wide $\mathrm{ZnO}$ bandgap, whereas the visible emission is attributed to oxygen vacancy and surface defects, which formed high-density surface trap states [29-31]. Roy et al. [32] reported a similar result (related to PL intensity in UV and visible regions) due to nitrogen impurities for $\mathrm{ZnO}$ tetrapods grown by thermal evaporation of $\mathrm{Zn}$ under a dry $\mathrm{N}_{2}$ flow passed through water vapor. The appearance of a new $\mathrm{PL}$ edge in the blue region at $398 \mathrm{~nm}(3.11 \mathrm{eV})$ after 

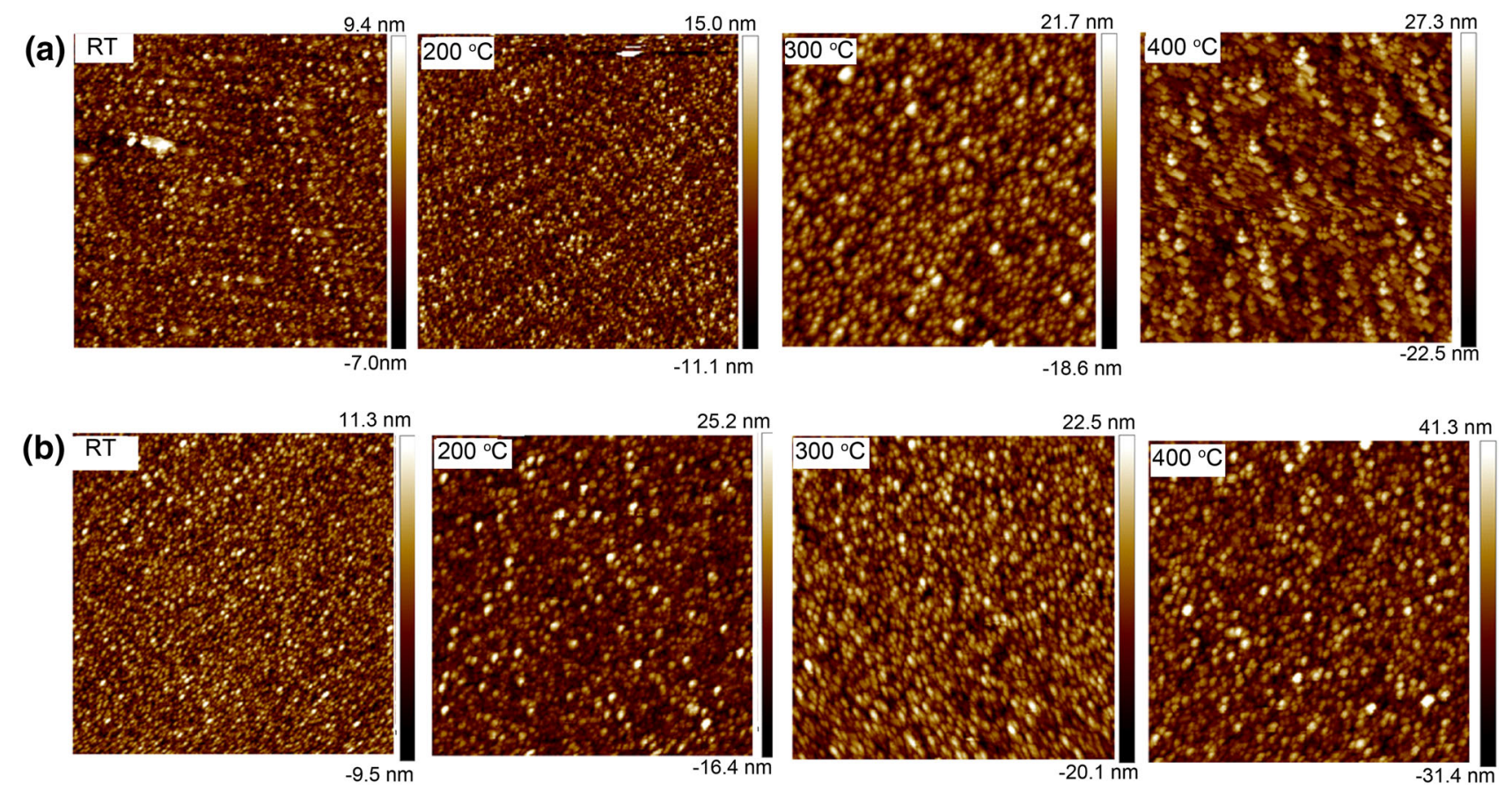

Fig. 4 AFM images of the $\mathrm{ZnO}$ nanostructure deposited at different substrate temperatures (dimension of the specimens is $5 \mu \mathrm{m} \times 5 \mu \mathrm{m}$ ): $\mathbf{a}$ as deposited, b after annealing at $500{ }^{\circ} \mathrm{C}$ for $2 \mathrm{~h}$ under $\mathrm{N}_{2}$ flow

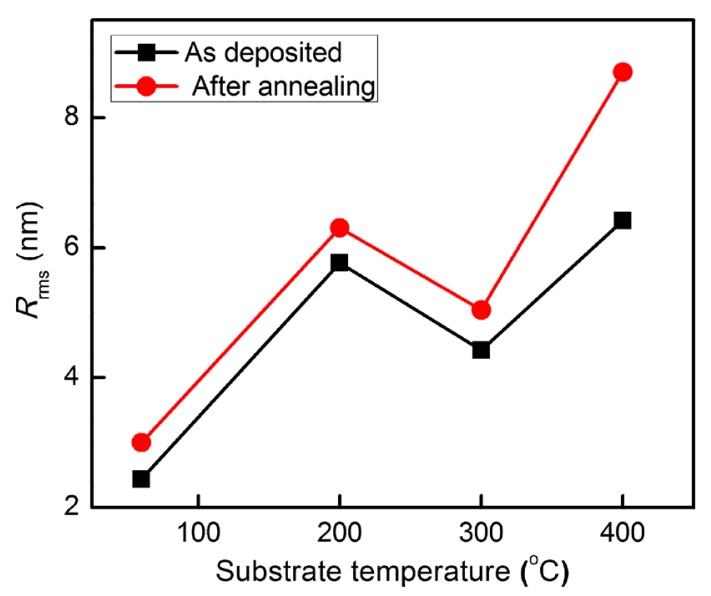

Fig. $5 R_{\text {rms }}$ of the $\mathrm{ZnO}$ nanostructure deposited at different substrate temperatures

annealing for the $\mathrm{ZnO}$ deposited at RT can be seen (Fig. 7b). This value is comparable with the energy interval between the bottom of the conduction band and the $\mathrm{Zn}$ vacancy $\left(V_{\mathrm{Zn}}=3.06 \mathrm{eV}\right)$ reported by Elilarassi and Chandrasekaran [17]. To investigate the optical properties of the $\mathrm{ZnO}$ nanostructures deposited at different temperatures and the effects of annealing on the energy bandgap $\left(E_{\mathrm{g}}\right)$, we deposited $\mathrm{ZnO}$ onto a glass substrate by applying the same parameters used in the $\mathrm{SiO}_{2}$ substrate. The absorption coefficient near the absorption edge was calculated using the following equation [33]: $\propto=\frac{2.3026 A}{d}$,

where $d$ is the film thickness and $A$ is the absorbance. The fundamental absorption for $\mathrm{ZnO}$ may have resulted from the allowed direct transitions described by the well-known relation [34]:

$\propto h v=A_{\mathrm{a}}\left(h v-E_{\mathrm{g}}\right)^{1 / 2}$,

where $h v$ is the incident photon energy and $A_{a}$ is the characteristic parameter that is independent of the photon energy for respective transitions. The bandgap was estimated by plotting $\left((\propto h v)^{2}\right.$ versus $h v$. The calculated values of $E_{\mathrm{g}}$ are listed in Table 2 . The $E_{\mathrm{g}}$ generally decreased after annealing (Fig. 8). This result is consistent with that obtained by Elilarassi and Chandrasekaran [17], who studied the effects of annealing from 350 to $550{ }^{\circ} \mathrm{C}$ on the optical properties of $\mathrm{ZnO}$ thin films prepared by a modified liquid flow deposition method. The decrease in the energy bandgap after annealing may be attributed to the increased density of oxygen vacancy defects in the $\mathrm{ZnO}$ films, which enhanced the density of the induced mid-gap states . In turn, the optical bandgap decreased [28]. The $E_{\mathrm{g}}$ of the as-deposited $\mathrm{ZnO}$ film at $400{ }^{\circ} \mathrm{C}(3.32 \mathrm{eV})$ is higher than those of other samples, which implies the complete or partial removal of the mid-gap states [28]. Figure 9 shows the semi-logarithmic plots of the current as a function of the bias voltage $(I-V)$ at $\mathrm{RT}$ for the $\mathrm{Pd} /$ undoped $\mathrm{ZnO} / \mathrm{Pd}$ 
(a)

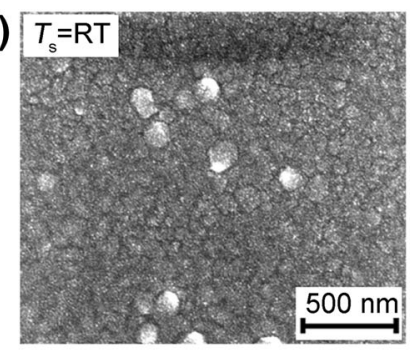

(b)

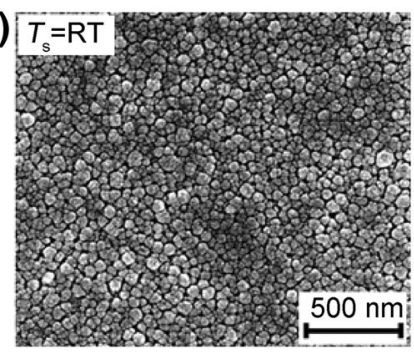

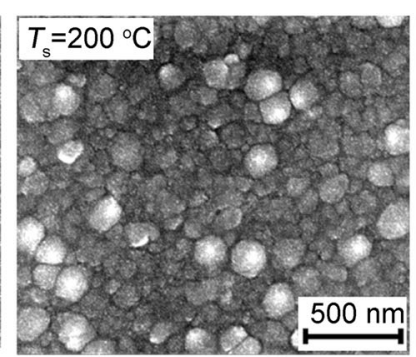

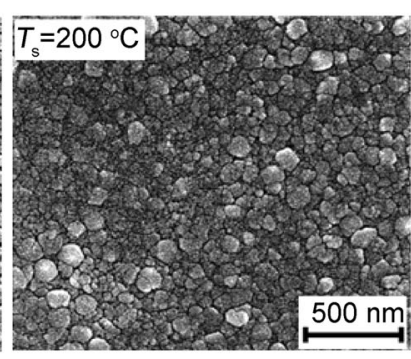

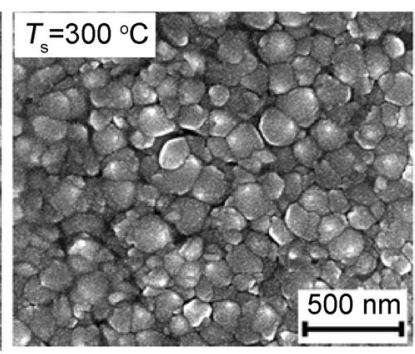
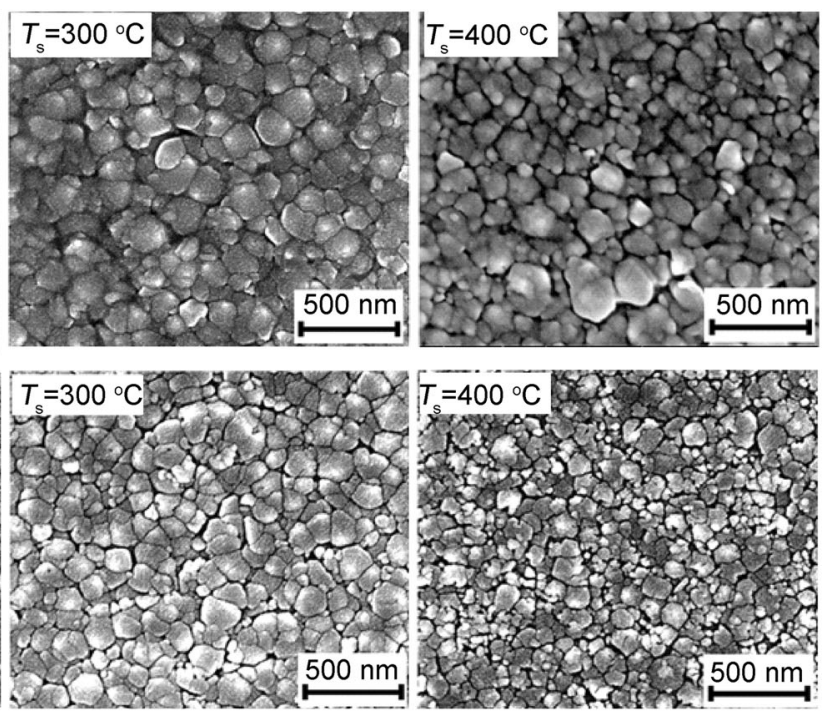

Fig. 6 Different magnifications of the FESEM images of the $\mathrm{ZnO}$ nanostructure at different deposition temperatures: $\mathbf{a}$ as deposited, $\mathbf{b}$ after annealing at $500{ }^{\circ} \mathrm{C}$ for $2 \mathrm{~h}$ under $\mathrm{N}_{2}$ flow
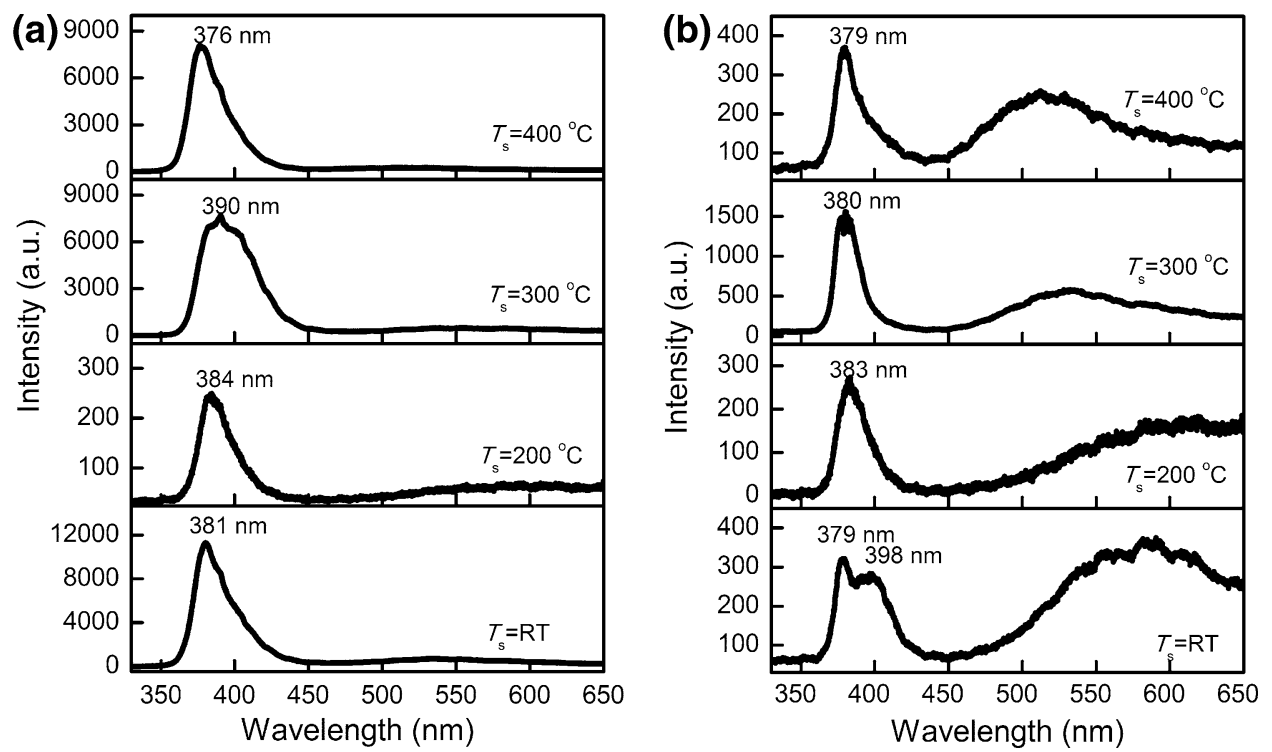

Fig. 7 Room-temperature PL spectra of the $\mathrm{ZnO}$ films at different deposition temperatures: $\mathbf{a}$ as deposited, $\mathbf{b}$ after annealing at $500{ }^{\circ} \mathrm{C}$ for $2 \mathrm{~h}$ under $\mathrm{N}_{2}$ flow

Schottky diodes before and after annealing at $500{ }^{\circ} \mathrm{C}$ for $2 \mathrm{~h}$ under an $\mathrm{N}_{2}$ flow. At a low forward bias voltage, the $I-$ $V$ characteristics are initially linear but then deviate considerably from linearity because of series resistance which is affected by the interface layer between $\mathrm{Pd}$ and $\mathrm{ZnO}$, thus a non-ideal forward $I-V$ can be achieved [35]. The Schottky diode parameters, such as the barrier height $\left(\emptyset_{\mathrm{B}}\right)$ and ideality factor $(n)$ were calculated using the $I-V$ relation described using the thermionic emission model [7-9]:
$I=I_{\mathrm{s}}\left[\exp \left(\frac{q V}{n k T}\right)-1\right]$

where $n$ is equal to 1 for an ideal Schottky diode, $V$ is the applied voltage, $k$ is Boltzmann constant, and $T$ is the absolute temperature. The saturation current, $I_{\mathrm{s}}$, is given by the following relation [5, 7-9]:

$I_{\mathrm{s}}=A^{*} S_{\mathrm{a}} T^{2} \exp \left(-\frac{q \emptyset_{\mathrm{B}}}{k T}\right)$, 
Table 2 Schottky properties and energy bandgap of the $\mathrm{ZnO}$ photodetectors deposited at different temperatures before (as deposited) and after annealing at $500{ }^{\circ} \mathrm{C}$ for $2 \mathrm{~h}$ under $\mathrm{N}_{2}$ flow

\begin{tabular}{|c|c|c|c|c|c|c|c|c|c|c|}
\hline \multirow[t]{2}{*}{$T_{\mathrm{s}}\left({ }^{\circ} \mathrm{C}\right)$} & \multicolumn{5}{|c|}{ As deposited } & \multicolumn{5}{|c|}{ After Annealing } \\
\hline & $E_{\mathrm{g}}(\mathrm{eV})$ & $I_{\mathrm{s}}(\mu \mathrm{A})$ & $\emptyset_{\mathrm{B}}(\mathrm{eV})$ & $n$ & Leakage current $(\mu \mathrm{A})$ & $E_{\mathrm{g}}(\mathrm{eV})$ & $I_{\mathrm{s}}(\mu \mathrm{A})$ & $\emptyset_{\mathrm{B}}(\mathrm{eV})$ & $n$ & Leakage current $(\mu \mathrm{A})$ \\
\hline RT & 3.3 & 2.8 & 0.679 & 9.67 & $1.73 \times 10^{4}$ & 3.22 & 2.85 & 0.678 & 8.16 & 1.91 \\
\hline 200 & 3.28 & 1.05 & 0.704 & 18.69 & 28.9 & 3.24 & 1.27 & 0.699 & 13.2 & 2.5 \\
\hline 300 & 3.28 & 0.393 & 0.73 & 14.95 & 42 & 3.24 & 0.581 & 0.72 & 12.29 & 1.2 \\
\hline 400 & 3.32 & 0.0659 & 0.776 & 10.79 & 12.9 & 3.28 & 0.081 & 0.77 & 13.13 & 0.17 \\
\hline
\end{tabular}

where $A^{*}$ is the effective Richardson constant with a theoretical value of $32 \mathrm{~A} \mathrm{~cm}^{-2} \mathrm{~K}^{-2}$ [5, 7-9]. The Schottky contact area $\left(S_{\mathrm{a}}\right)$ was $0.25 \mathrm{~cm}^{2}$. From the $I_{\mathrm{s}}$ values obtained from the intercept of the linear portion of the forward $I-$ $V$ characteristic plots (Fig. 9a, b), $\emptyset_{\mathrm{B}}$ can be calculated from the following relationship [9]:

$\emptyset_{\mathrm{B}}=\frac{k T}{q} \ln \frac{S_{\mathrm{a}} A^{*} T^{2}}{I_{\mathrm{s}}}$

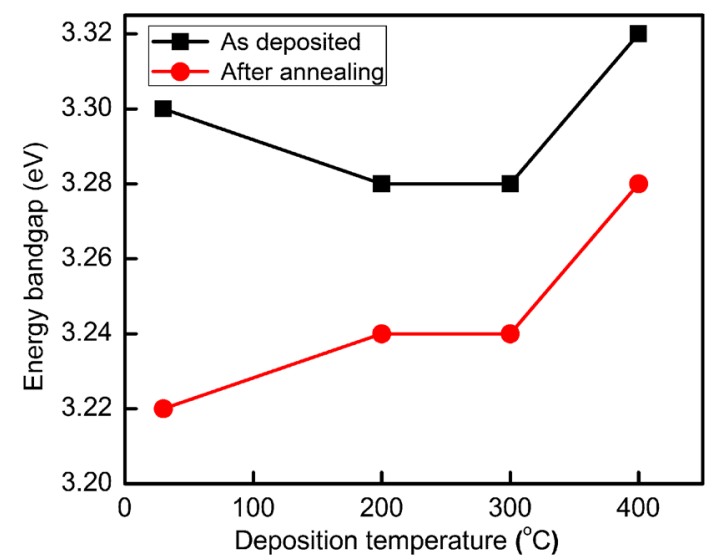

Fig. 8 Energy bandgap of $\mathrm{ZnO}$ at different deposition temperatures

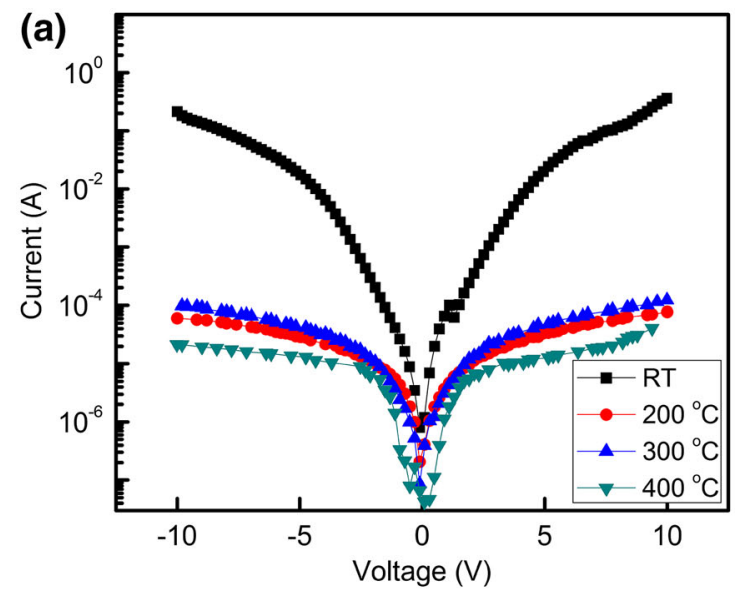

$n$ was obtained from the gradient of the linear region of the semi-logarithmic portion of the forward $I-V$ plots after applying the following relation [9]:

$n=\frac{q}{k T}\left(\frac{\Delta V}{\Delta \ln I}\right)$.

The calculated values of $I_{\mathrm{s}}, \emptyset_{\mathrm{B}}$, and $n$ are listed in Table 2. Figure 10 shows the variations in $I_{\mathrm{s}}, \emptyset_{\mathrm{B}}$, and $n$ with the $T_{\mathrm{s}}$, respectively. The $\emptyset_{\mathrm{B}}$ values increased with an increase in $T_{\mathrm{s}}$ (Fig. 10b), contrary to the behavior of $I_{\mathrm{s}}$ (Fig. 10a). The values of $\emptyset_{B}$ were between 0.614 and $0.85 \mathrm{eV}$, which were larger than those obtained for resistively evaporated $\mathrm{Pd}$ on $\mathrm{ZnO}$ Schottky diode $(0.52 \mathrm{eV})$ by Mtangi et al. [9], $n$ increased with an increase in $T_{\mathrm{s}}$ to reach the maximum value (14.95) at $300{ }^{\circ} \mathrm{C}$ and then decreased with further increase in $T_{\mathrm{s}}$ (Fig. 10c). This behavior is consistent with that obtained by Han et al. [36] for Al-doped ZnO Schottky diode on $\mathrm{GaN}$ substrate prepared via electron beam evaporation. The high values of $n$ can be attributed to the presence of interfacial thin native oxide layer between the $\mathrm{Pd}$ and $\mathrm{ZnO}$ interface and/or barrier inhomogeneities [35]. Generally, $\emptyset_{\mathrm{B}}$ and $n$ decreased after annealing, whereas $I_{\mathrm{S}}$ increased. The decrease in $\emptyset_{\mathrm{B}}$ can be attributed to the enhanced

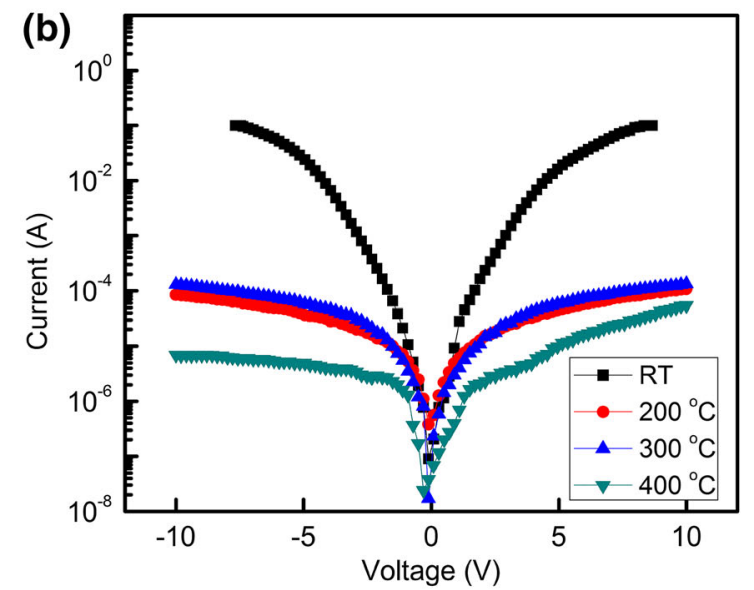

Fig. 9 The $I-V$ characteristics of the $\mathrm{Pd} / \mathrm{ZnO} / \mathrm{Pd}$ photodetector deposited at different substrate temperatures: $\mathbf{a}$ as deposited, $\mathbf{b}$ after annealing at $500{ }^{\circ} \mathrm{C}$ for $2 \mathrm{~h}$ under $\mathrm{N}_{2}$ flow 

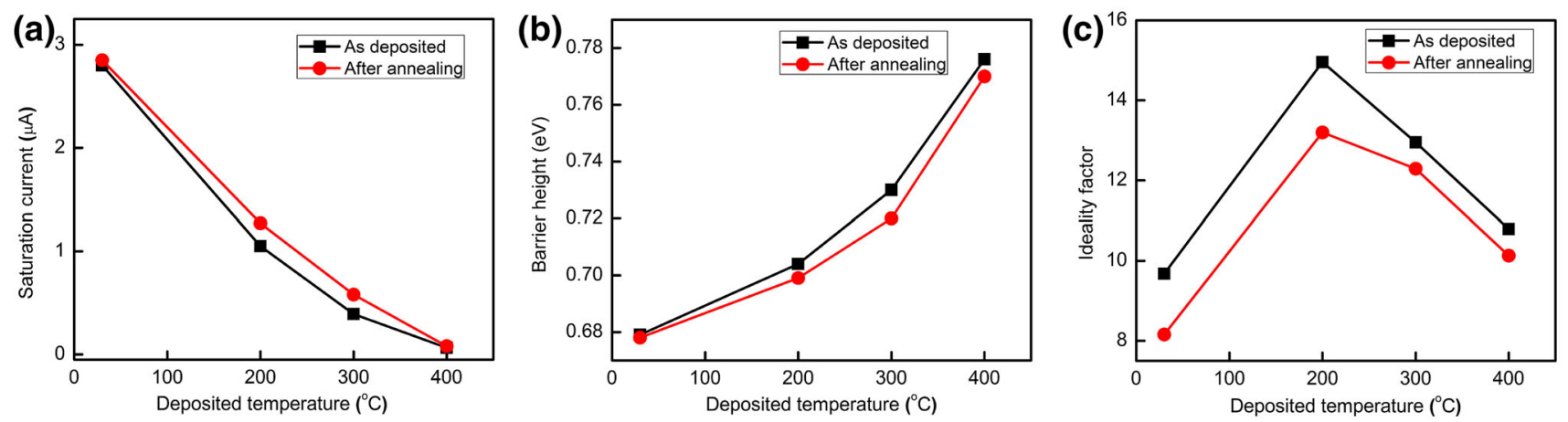

Fig. 10 Schottky properties of the $\mathrm{ZnO}$ photodetectors as a function of deposition temperatures: a saturation current, $\mathbf{b}$ barrier height, $\mathbf{c}$ ideality factors
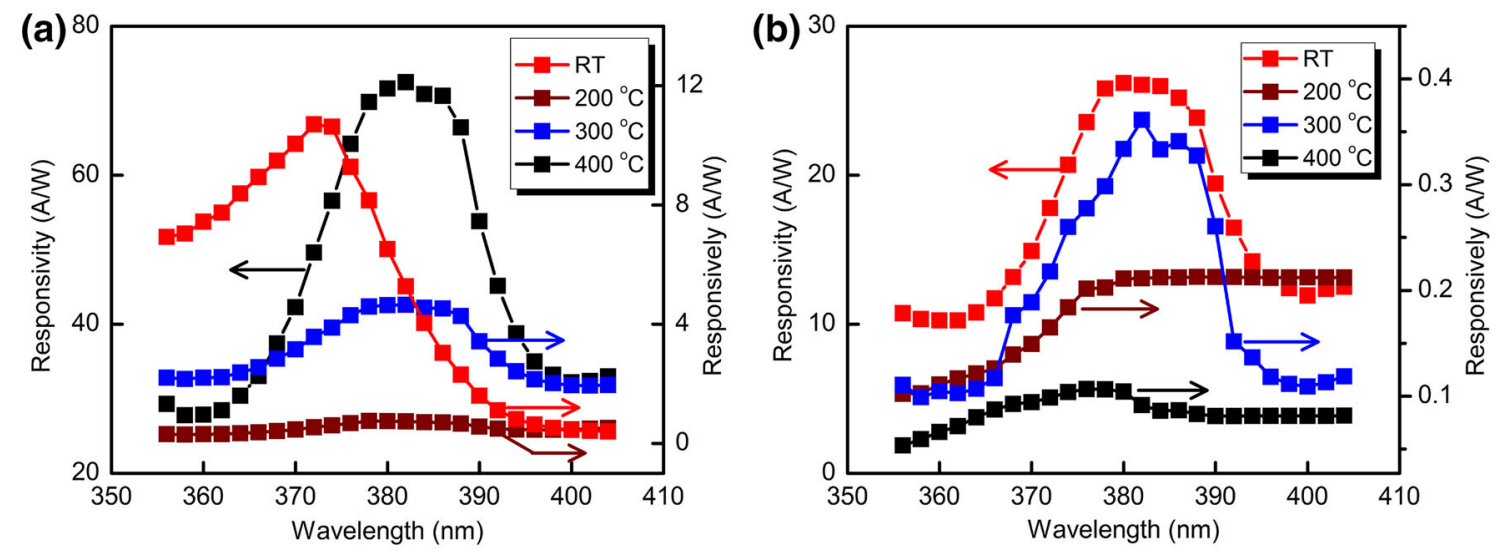

Fig. 11 Spectral response as a function of wavelength at a bias of $5 \mathrm{~V}$ deposited at different temperatures: $\mathbf{a}$ as deposited, $\mathbf{b}$ after annealing at $500{ }^{\circ} \mathrm{C}$ for $2 \mathrm{~h}$ under $\mathrm{N}_{2}$ flow

tunneling or defect-induced changes in doping within the depletion region after high-temperature annealing and/or increase in carrier concentration [36, 37], leading to the increase in the Fermi level and a decrease in the Schottky barrier height according to the following equations [36]:

$\emptyset_{\mathrm{B}}=\emptyset_{\mathrm{m}}-\chi$,

$\emptyset_{\mathrm{m}}=E_{0}-E_{\mathrm{F}}$,

where $\emptyset_{\mathrm{m}}$ is the work function of the metal, $\chi$ is electronic affinity of the semiconductor, $E_{0}$ stands for the stillness electronic energy in vacuum, and $E_{\mathrm{F}}$ is the Fermi level of the metal. The leakage current at a reverse bias of $5 \mathrm{~V}$ decreased remarkably after annealing, as observed from Table 2. However, the leakage current is related to the defects caused by the lattice mismatch and the point defects in the substrates as well as comes from the grain boundaries of the $\mathrm{ZnO}$ films [36]. At low $T_{\mathrm{s}}$, the leakage current is due to the resistance of $\mathrm{ZnO}$ films; however, at high $T_{\mathrm{s}}$, the grains increase in size and accumulated grain boundaries that lead to numerous dislocations becomes the main factor for the leakage current [36].
To investigate the UV photoresponse performance of $\mathrm{Pd} /$ undoped $\mathrm{ZnO} / \mathrm{Pd}$ Schottky diodes, the spectral photoresponse is considered an important parameter of the detector, which determines the efficiency for detection at a wavelength range. The photoresponse, $R_{\lambda}$, is given by [38]:

$R_{\lambda}=I_{\mathrm{Ph}} / P_{\text {in }}$,

where $P_{\text {in }}$ is the input power of light. Figure 11 depicts the spectral photoresponses of the $\mathrm{ZnO}$ photodetector biased at $5 \mathrm{~V}$. For the as-deposited samples, the $I_{\mathrm{ph}}$ increased with increasing wavelength to achieve a photoresponsivity of $10.7,0.75,4.64$, and $70.87 \mathrm{~A} / \mathrm{W}$ at a wavelength of 372 , 378,380 , and $380 \mathrm{~nm}$ for the $\mathrm{ZnO}$ photodetectors deposited at RT, 200, 300 , and $400{ }^{\circ} \mathrm{C}$, respectively. When the wavelength further increased, the photoresponsivity decreased (Fig. 11a). The photoresponsivity of the $\mathrm{ZnO}$ photodetectors deposited at RT and $400{ }^{\circ} \mathrm{C}$ fell sharply in the visible region compared with the other samples (Fig. 11a), indicating the high selectivity in the UV region. These values of photoresponsivities decreased after annealing and reached $0.212,0.361$, and $0.106 \mathrm{~A} / \mathrm{W}$ at wavelengths of 386,408 , and $380 \mathrm{~nm}$ for the samples 

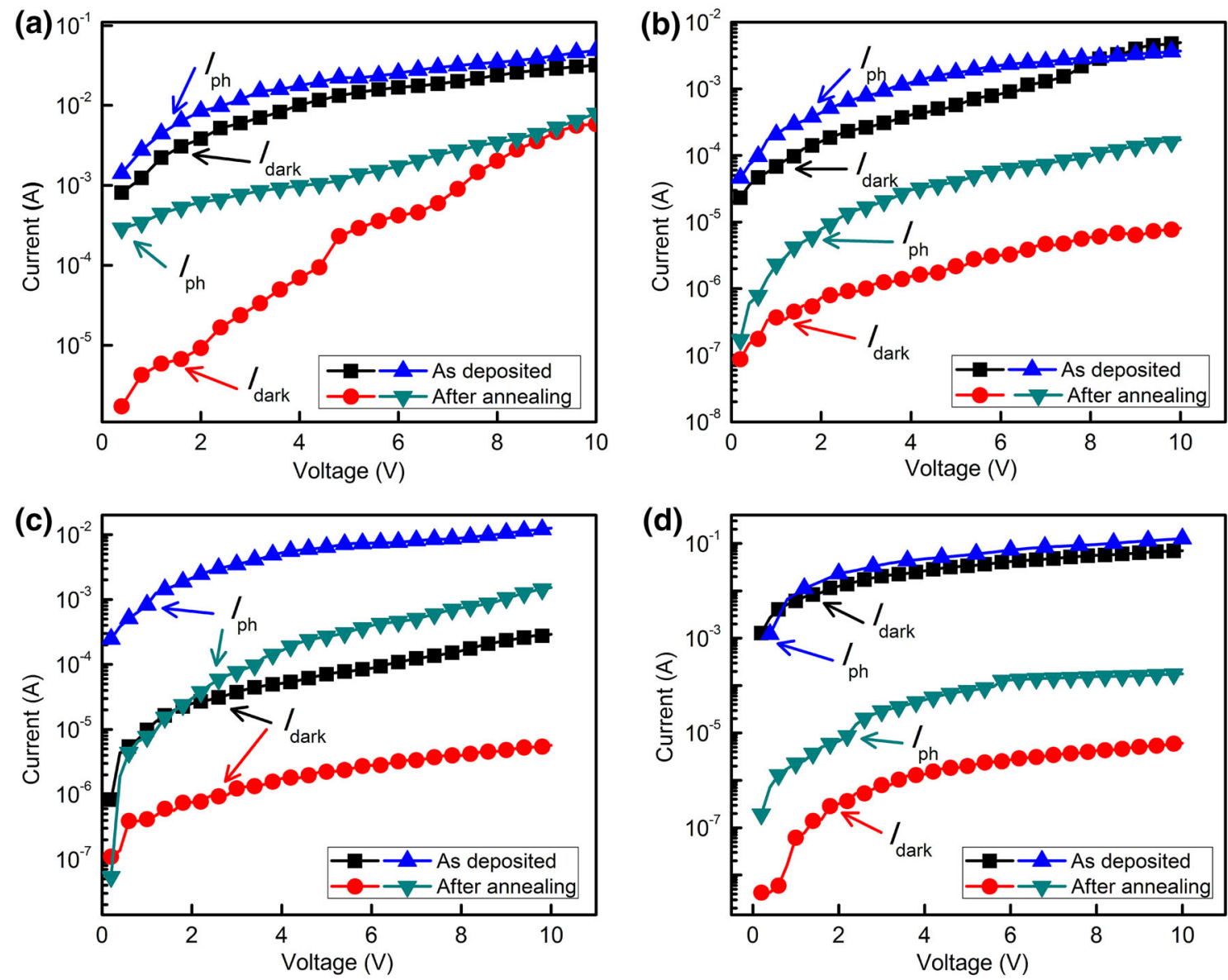

Fig. 12 The $I-V$ characteristics of the $\mathrm{Pd} / \mathrm{ZnO} / \mathrm{Pd}$ photodetectors before and after annealing at $500{ }^{\circ} \mathrm{C}$ in darkness and under UV illumination $\left(385 \mathrm{~nm}, 1.12 \mathrm{~mW} / \mathrm{cm}^{2}\right)$ deposited at different temperatures: a RT, b $200{ }^{\circ} \mathrm{C}, \mathbf{c} 300{ }^{\circ} \mathrm{C}, \mathbf{d ~} 400{ }^{\circ} \mathrm{C}$

deposited at 200,300 , and $400{ }^{\circ} \mathrm{C}$, respectively, contrary to the increase for the samples deposited at RT which reached $26.18 \mathrm{~A} / \mathrm{W}$ at $374 \mathrm{~nm}$. This increase in photoresponsivity may have been caused by the intrinsic donor defects, such as oxygen vacancies, zinc interstitials, and/or $\mathrm{N}_{2}$ impurities (Fig. 7b). These defects generate many free electrons after annealing, causing the increase in photoresponsivity. However, the decrease in photoresponsivities for the samples deposited at 200,300 , and $400{ }^{\circ} \mathrm{C}$ can be attributed to lower $I_{\mathrm{dark}}$ and $I_{\mathrm{ph}}$ after annealing. Figure 12 depicts the $I-$ $V$ characteristics in the darkness and under UV wavelength of $385 \mathrm{~nm}$ for the $\mathrm{ZnO}$ photodetectors deposited at different $T_{\mathrm{s}}$. The difference between $I_{\mathrm{dark}}$ and $I_{\mathrm{ph}}$ became higher compared with the as-deposited values, indicating high photosensitivity $(S)$. The decrease in $I_{\text {dark }}$ may have been caused by the increase in porosity (Fig. 6b), which in turn increased the $R_{\mathrm{rms}}$ (Fig. 5), leading to the formation of an enhanced depletion layer formed around the crystallite surface boundaries by adsorbing extra oxygen molecules in the dark environment.

The photosensitivity $(S)$ of the photodetectors can be defined using the following equation $[39,40]$ :
$S=\left[\frac{\left(I_{\mathrm{ph}}-I_{\mathrm{dark}}\right)}{I_{\mathrm{dark}}}\right] \times 100 \%$.

Based on the $I-V$ curve and Eq. (13), the $I_{\text {dark }}, I_{\mathrm{ph}}$, and $S$ under a $5 \mathrm{~V}$ applied bias are listed in Table 3. Figure 13 shows the photosensitivity as a function of $T_{\mathrm{s}}$. The photosensitivity exhibits the same behavior for the asdeposited and annealed samples, which increases as $T_{\mathrm{s}}$ increases to reach the maximum values of $8.98 \times 10^{3}$ and $12.51 \times 10^{3} \%$ at $300{ }^{\circ} \mathrm{C}$ before and after annealing, respectively. This result is higher than that obtained by Chen et al. [41] $\left(S=11.72 \times 10^{3} \%\right)$ for the $\mathrm{ZnO}$ thin films prepared by sol-gel on quartz substrate after annealing at $650{ }^{\circ} \mathrm{C}$ for $1 \mathrm{~h}$ in pure oxygen atmosphere using $\mathrm{IrO}_{2}$ as spiral electrodes, and comparable with that obtained by Yuan et al. [40] for single $\mathrm{ZnO}$ nanobelt $\left(S=1.15 \times 10^{4} \%\right)$ using a bias voltage of $5 \mathrm{~V}$. The photosensitivity decreased with further increase of $T_{\mathrm{s}}$ to reach 73 and $36.71 \times 10^{2} \%$ for the as-deposited and annealed samples, respectively. Overall, the photosensitivity of all the samples increased after annealing (approximately two order of magnitude for the sample deposited at $400{ }^{\circ} \mathrm{C}$ ), to provide more evidence 
Table 3 Photosensitivity properties with response and recovery time of the $\mathrm{ZnO}$ photodetectors deposited at different temperatures before (as deposited) and after annealing at $500{ }^{\circ} \mathrm{C}$ for $2 \mathrm{~h}$ under $\mathrm{N}_{2}$ flow

\begin{tabular}{|c|c|c|c|c|c|c|c|c|c|c|}
\hline \multirow[t]{2}{*}{$T_{\mathrm{s}}\left({ }^{\circ} \mathrm{C}\right)$} & \multicolumn{5}{|l|}{ As deposited } & \multicolumn{5}{|c|}{ After annealing } \\
\hline & $I_{\text {dark }}(\mu \mathrm{A})$ & $I_{\mathrm{ph}}(\mu \mathrm{A})$ & $S(\%)$ & $t_{\mathrm{res}}(\mathrm{s})$ & $t_{\mathrm{rec}}(\mathrm{s})$ & $I_{\text {dark }}(\mu \mathrm{A})$ & $I_{\mathrm{ph}}(\mu \mathrm{A})$ & $S(\%)$ & $t_{\mathrm{res}}(\mathrm{s})$ & $t_{\mathrm{rec}}(\mathrm{s})$ \\
\hline RT & $1.464 \times 10^{4}$ & $2.22 \times 10^{4}$ & 51.7 & 28 & 4 & $2.93 \times 10^{2}$ & $13.8 \times 10^{2}$ & 370.37 & 1.019 & 0.69 \\
\hline 200 & $0.631 \times 10^{3}$ & $1.8 \times 10^{3}$ & $1.85 \times 10^{2}$ & 8 & 2 & 2.293 & 43.57 & $1.8 \times 10^{3}$ & 0.562 & 0.41 \\
\hline 300 & 74.33 & $6.75 \times 10^{3}$ & $8.98 \times 10^{3}$ & 18 & 4 & 2.259 & 284.9 & $12.51 \times 10^{3}$ & 0.508 & 0.466 \\
\hline 400 & $3.49 \times 10^{4}$ & $6.04 \times 10^{4}$ & 73 & 18 & 104 & 2.193 & 82.7 & $36.71 \times 10^{2}$ & 1.282 & 0.676 \\
\hline
\end{tabular}

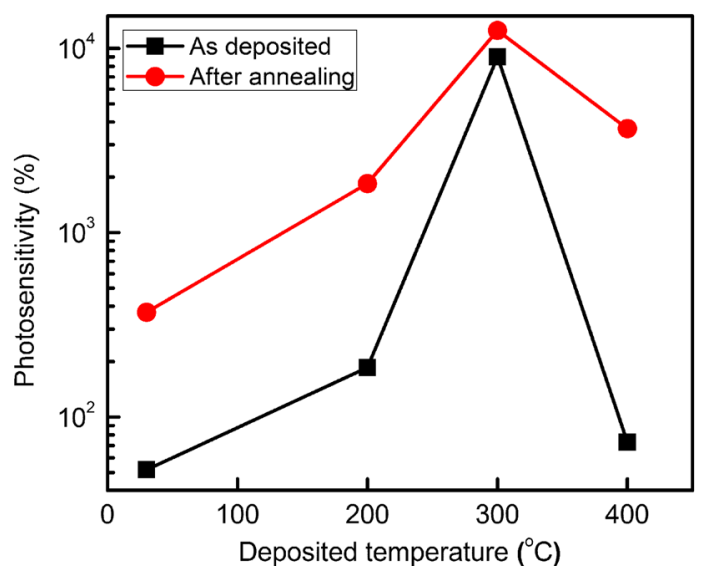

Fig. 13 Photosensitivity as a function of deposited temperature before and after annealing

for improved photosensitivity after annealing. The large photosensitivity can be ascribed to the presence of abundant carriers collected under illumination in the $\mathrm{ZnO}$ film [15].

To confirm the good performance of the UV photodetector, reproducibility of the devices has been examined by cyclically switching the UV light on and off. Figures 14 and 15 show the $I_{\mathrm{ph}}$ as a function of time intervals ( $I-$ t) before (as deposited) and after annealing at $500{ }^{\circ} \mathrm{C}$, respectively. The $I_{\mathrm{ph}}$ increased as the photodetectors were illuminated by UV light. When the UV light was switched off, the current recovered to their initial value. For the asdeposited photodetector devices at different $T_{\mathrm{s}}$, no saturation was obtained in the $I_{\mathrm{ph}}$ even at long UV exposure time (Fig. 14), whereas the $I_{\mathrm{ph}}$ increased (decreased) sharply to reach the maximum (minimum) value (steady state) under UV light on (off) after annealing at $500{ }^{\circ} \mathrm{C}$ (Fig. 15), indicating improved response and recovery time after annealing. For the photodetector device deposited at RT, the photoresponse after annealing deteriorated compared with that deposited at high temperature. This result may have been caused by the existence of $V_{\mathrm{Zn}}$ level and surface defect in the $\mathrm{ZnO}$ sample after annealing, as observed from the PL spectrum (Fig. 7b). The $I_{\text {dark }}$ of the as-deposited photodetector at $200{ }^{\circ} \mathrm{C}$ (Fig. 14b), as well as that deposited at RT (Fig. 15a) and $300{ }^{\circ} \mathrm{C}$ (Fig. 15d) after annealing, did not recover to the initial values with respect to time, which seems to be related to persistent photoconductivity effect, which is attributed to the presence of native defects of the $\mathrm{ZnO}$ nanostructures [42]. UV illumination generates electron-holes, which in turn increases the $I_{\mathrm{ph}}$. When UV light is switched off, both band-to-band recombination and trapping of electrons into lower-energy states occur, leaving behind small amount of electrons that did not recombine to remain available in the conduction band, causing an additional amount of $I_{\text {dark }}$ after each UV pulse [42].

However, the response time, $t_{\text {res }}$, and recovery time, $t_{\text {rec }}$, ( $t_{\text {res }}$ is the time required to reach $\frac{e-1}{e}(\sim 63 \%$, where $e$ is the base of the natural logarithm) of the maximum $I_{\mathrm{ph}}$, while $t_{\operatorname{Rec}}$ is the time required to recover to $1 / e$ ( $\sim 37 \%$ of the maximum $I_{\mathrm{ph}}$ ) [14], are very important criteria for high performance photodetectors. The calculated $t_{\mathrm{res}}$ and $t_{\mathrm{rec}}$ are listed in Table 3, wherein all values decreased sharply after annealing, indicating the improved photoresponsivity. The as-deposited photodetectors at different $T_{\mathrm{s}}$ have been found to have very slow $t_{\text {res }}$ and $t_{\text {rec }}$ because no steady state was obtained. This result may have been caused by the presence of different amounts of defect concentration and a carrier relaxation process in the deep defect states, which are much slower than the surface process [43-45]. The reaction between the incident UV light and ionized vacancies of oxygen $\left(\mathrm{V}_{\mathrm{O}}^{+}\right)$and native defect can be written as [43]

$\mathrm{V}_{\mathrm{O}}^{+}(\mathrm{ZnO})+e(\mathrm{ZnO}) \rightarrow \mathrm{V}_{\mathrm{O}}$

$\frac{1}{2} \mathrm{O}_{2}(\mathrm{~g})+\mathrm{V}_{\mathrm{O}}(\mathrm{ZnO}) \rightarrow \mathrm{O}_{\mathrm{O}}(\mathrm{ZnO})$.

In addition, the highest $R_{\mathrm{rms}}$ and residual stress can reduce UV photoresponse and increase $R_{\text {res }}$ significantly [16]. However, all devices after annealing exhibited shorter response and recovery time between 0.508 to $1.282 \mathrm{~s}$ and 0.41 to $0.69 \mathrm{~s}$, respectively. After annealing, the photodetector deposited at $300{ }^{\circ} \mathrm{C}$ had the shortest $t_{\text {res }}$ of $0.508 \mathrm{~s}$, whereas that deposited at $200{ }^{\circ} \mathrm{C}$ had shortest $t_{\text {rec }}$ of $0.41 \mathrm{~s}$. The photoresponse of the $\mathrm{ZnO}$ nanostructure strongly depends on electron-hole generation, photodesorption 

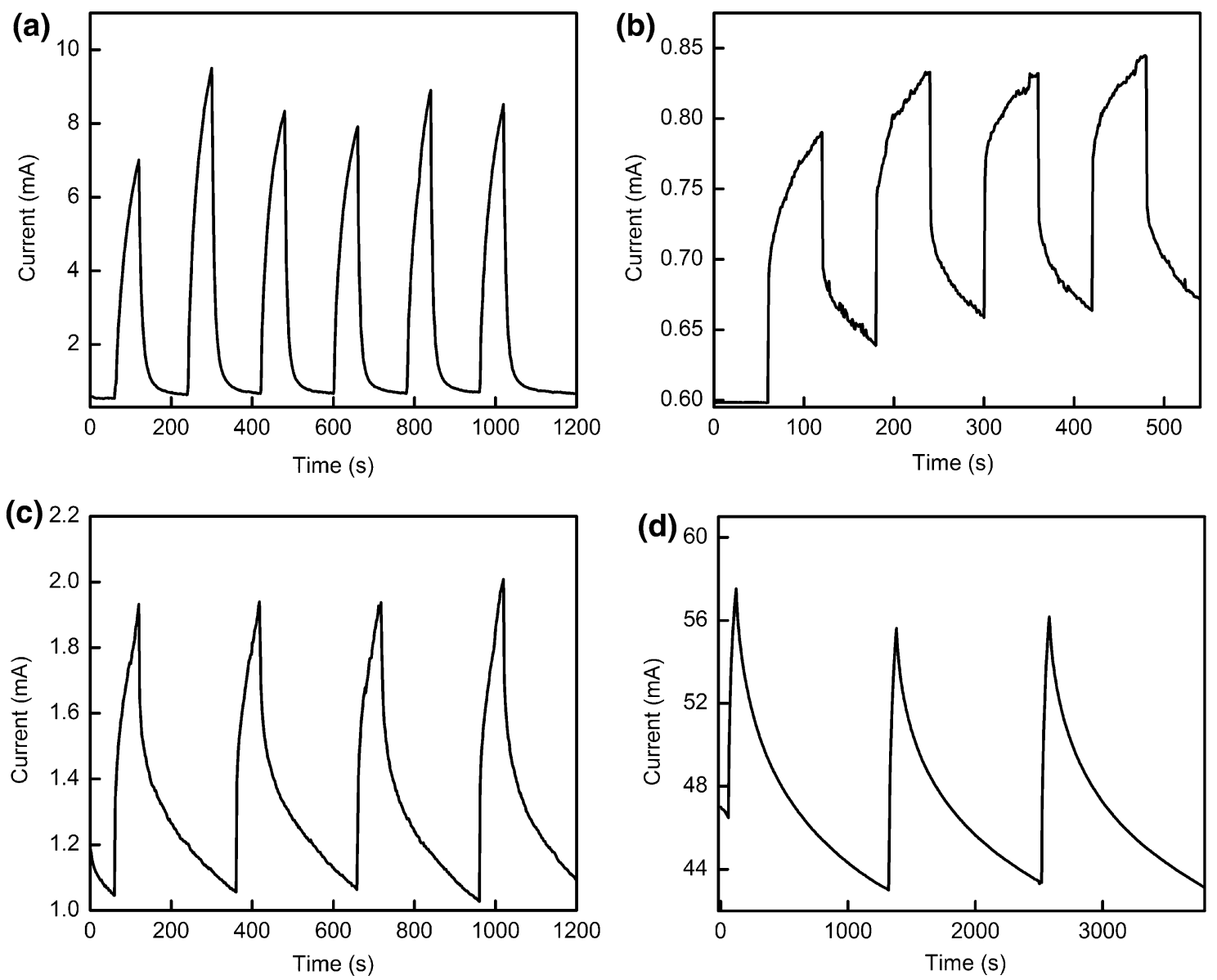

Fig. 14 Response-time spectra of the as-deposited $\mathrm{ZnO}$ photodetectors with UV light illumination $\left(385 \mathrm{~nm}, 1.12 \mathrm{~mW} / \mathrm{cm}^{2}\right)$ turned on and off repeatedly at different deposition temperatures with a bias voltage of $5 \mathrm{~V}$

processes, and surface adsorption, and the fast or slow response depends on the time taken to reach the equilibrium rate of oxygen desorption and readsorption processes [14]. In the present study, annealing at $500{ }^{\circ} \mathrm{C}$ under $\mathrm{N}_{2}$ flow may have changed the equilibrium defect concentration, as shown in the PL spectrum (Fig. 7b), in which, the rates of oxygen desorption and readsorption processes are significantly improved and immediately reach the equilibrium rate. Thus, faster photoresponse and high photosensitivity are obtained (Figs. 13, 15) [14]. Figure 15h shows the current as function of time with an applied bias voltage of $2 \mathrm{~V}$ for the $\mathrm{ZnO}$ photodetector devices deposited at different $T_{\mathrm{s}}$ after annealing. The photosensitivities of the $\mathrm{ZnO}$ photodetector deposited at 200, 300, and $400{ }^{\circ} \mathrm{C}$ using $405 \mathrm{~nm}$ UV light were $1.17 \times 10^{2}, 2.25 \times 10^{2}$, and $14.82 \times 10^{2}$, respectively.

The mechanism of the photoresponse can be explained in terms of oxygen chemisorptions, which have a central role in regulating the dark conductivity and the photoconductivity of the $\mathrm{ZnO}$ nanostructure. Under darkness (Fig. 16a), the oxygen molecules $\mathrm{O}_{2(\mathrm{~g})}$ were adsorbed on the $\mathrm{ZnO}$ surface as $\mathrm{O}_{2}^{-}(\mathrm{ad})$ and/or $\mathrm{O}_{2}^{2-}(\mathrm{ad})$ by trapping the free electrons, leading to a decrease in the density and the mobility of the carrier by creating a depletion layer at the grain boundaries near the surface [28, 39, 46-49].

$\mathrm{O}_{2}(\mathrm{~g})+e^{-} \rightarrow \mathrm{O}_{2}^{-}(\mathrm{ad})$,

$\mathrm{O}_{2}(\mathrm{~g})+2 e^{-} \rightarrow \mathrm{O}_{2}^{2-}(\mathrm{ad})$.

The tied oxygen ions cannot contribute to the conductivity of the film, producing a low conductive surface. When the $\mathrm{ZnO}$ is exposed to light illumination with the photon energy $(h v)$ greater than $E_{\mathrm{g}}$, electron-hole pairs are generated by the attracting the negatively charged oxygen ions $\mathrm{O}_{2}^{-}(\mathrm{ad})$ and/or $\mathrm{O}_{2}^{2-}(\mathrm{ad})$. Holes $\left(\mathrm{h}^{+}\right)$migrate to the surface (Fig. 16b) to recombine with the electrons in the ions $\mathrm{O}_{2}^{-}(\mathrm{ad})$, leaving behind unpaired electrons $\left(e^{-}\right)$. Thus, the neutralization prevents holes from recombining with electrons, and the unpaired electrons become the major carriers in the film and contribute to the $I_{\mathrm{ph}}$ (Fig. 16c) to enhance the conductance [28, 39, 46-49]: 

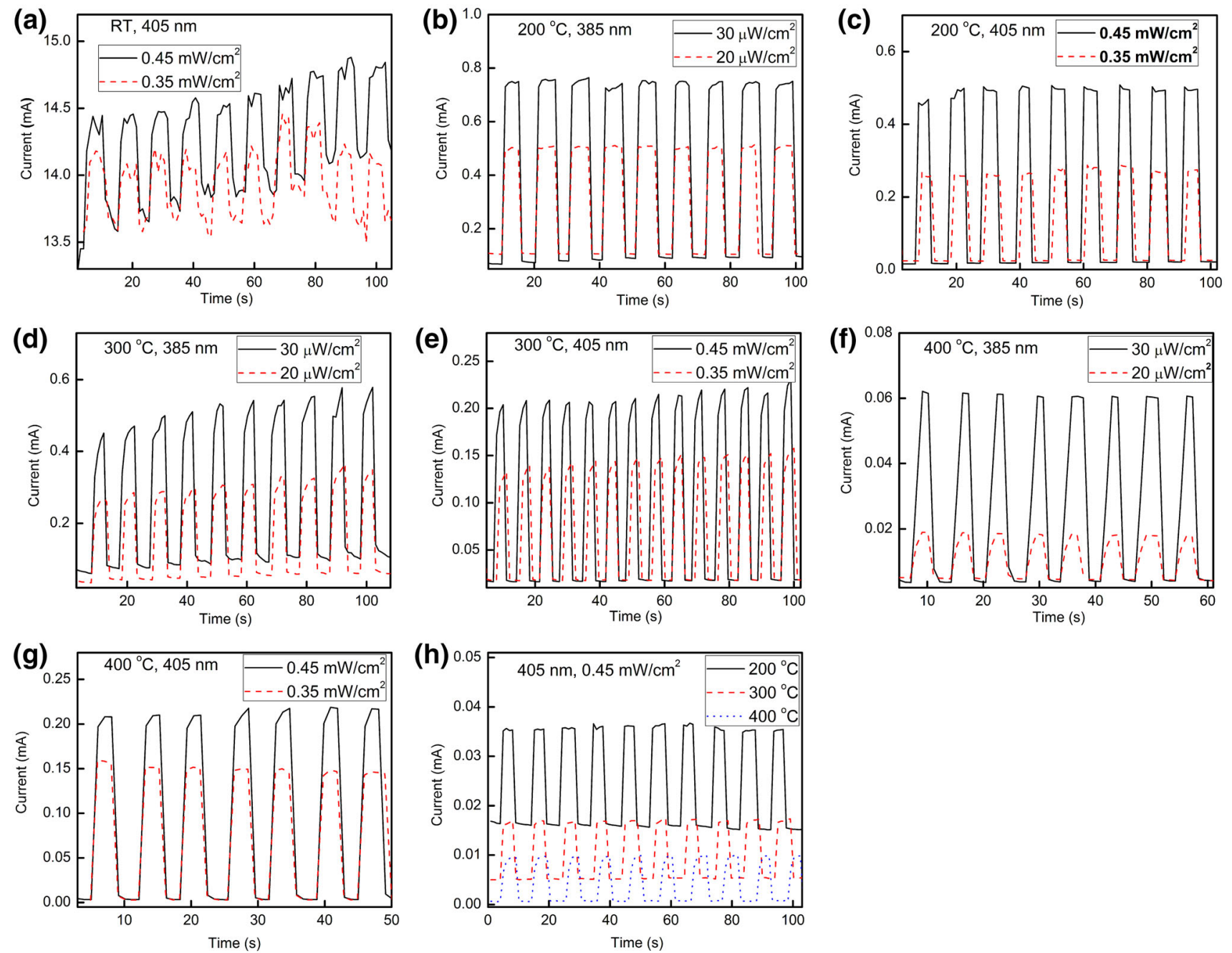

Fig. 15 Response-time spectra of the $\mathrm{ZnO}$ photodetectors with UV illumination turned on and off repeatedly under different conditions after annealing at $500{ }^{\circ} \mathrm{C}$ for $2 \mathrm{~h}$ : a $T_{\mathrm{s}}=\mathrm{RT}, \lambda_{\mathrm{UV}}=405 \mathrm{~nm}, U_{\mathrm{bia}}=5 \mathrm{~V} ; \mathbf{b} T_{\mathrm{s}}=200^{\circ} \mathrm{C}, \lambda_{\mathrm{UV}}=385 \mathrm{~nm}, U_{\mathrm{bia}}=5 \mathrm{~V} ; \mathbf{c} T_{\mathrm{s}}=200^{\circ} \mathrm{C}, \lambda_{\mathrm{UV}}=$ $405 \mathrm{~nm}, U_{\text {bia }}=5 \mathrm{~V} ; \quad$ d $\quad T_{\mathrm{s}}=300^{\circ} \mathrm{C}, \lambda_{\mathrm{UV}}=385 \mathrm{~nm}, U_{\text {bia }}=5 \mathrm{~V} ; \quad$ e $\quad T_{\mathrm{s}}=300^{\circ} \mathrm{C}, \lambda_{\mathrm{UV}}=405 \mathrm{~nm}, U_{\text {bia }}=5 \mathrm{~V} ; \quad$ f $\quad T_{\mathrm{s}}=400^{\circ} \mathrm{C}, \lambda_{\mathrm{UV}}=$ $385 \mathrm{~nm}, U_{\text {bia }}=5 \mathrm{~V} ; \mathbf{g} T_{\mathrm{s}}=400{ }^{\circ} \mathrm{C}, \lambda_{\mathrm{UV}}=405 \mathrm{~nm}, U_{\text {bia }}=5 \mathrm{~V} ; \mathbf{h} T_{\mathrm{s}}=200,300$ and $400{ }^{\circ} \mathrm{C}, \lambda_{\mathrm{UV}}=405 \mathrm{~nm}, U_{\text {bia }}=2 \mathrm{~V}$

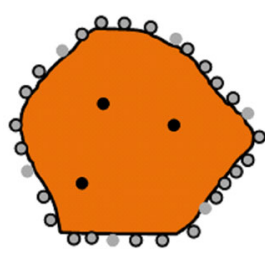

(a)

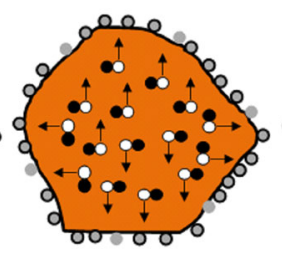

(b)

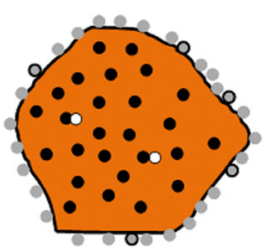

(c)
- $\mathrm{e}^{-} \quad \circ \mathrm{h}^{+} \bullet$ Electron-hole pair $\quad \mathrm{O}_{2}(\mathrm{~g}) \quad \circ \mathrm{O}_{2}^{-}(\mathrm{ad})$

Fig. 16 Schematic diagram of the photoconductive mechanism of the $\mathrm{ZnO}$ crystallite: a darkness; $\mathbf{b}$, $\mathbf{c}$ under light illumination

$h v \rightarrow e^{-}+\mathrm{h}^{+}$,

$\mathrm{h}^{+}+\mathrm{O}_{2}^{-}(\mathrm{ad}) \rightarrow \mathrm{O}_{2}(\mathrm{~g})$,
$2 \mathrm{~h}^{+}+\mathrm{O}_{2}^{2-}(\mathrm{ad}) \rightarrow \mathrm{O}_{2}(\mathrm{~g})$.

Switched off UV light decreases the hole concentration in the $\mathrm{ZnO}$ film, which in turn encourages the readsorption of oxygen molecules on the grain boundaries. Thus, the film conductivity decreases again [28]. The humidity effect on the photoresponse has been reported by Panda and Jacob [28], which demonstrated that the oxygen vacancy sites facilitate the water adsorption on the $\mathrm{ZnO}$ film surface more effectively than the oxygen molecules because of the single bond of the water molecules.

\section{Conclusions}

The combined effect of deposition temperature and annealing at $500{ }^{\circ} \mathrm{C}$ under $\mathrm{N}_{2}$ flow were investigated to 
characterize the $\mathrm{ZnO}$ nanostructures and its photoresponse properties. All annealed photodetector devices showed very fast $t_{\text {Res }}$ and $t_{\operatorname{Rec}}$ of $<1 \mathrm{~s}$ compared with the asdeposited devices.

After annealing, the $I_{\mathrm{ph}}$ of the $\mathrm{ZnO}$ photodetector deposited at $300{ }^{\circ} \mathrm{C}$ with a bias of $5 \mathrm{~V}$ were approximately two orders (126 time) of magnitude larger than the $I_{\text {dark }}$, with photosensitivity of $12.51 \times 10^{3} \%$. This result indicates that the optimum deposition temperature of the $\mathrm{ZnO}$ photodetectors was $300{ }^{\circ} \mathrm{C}$. The faster photoresponse and high value of the photosensitivity indicated high performance photodetectors with real time for UV detection. Excellent reproducibility and baseline stability of the photodetector was observed upon repeated exposure and removal of UV light after annealing. The photodetectors after annealing exhibited photosensitivities of two orders of magnitude at a bias voltage of $2 \mathrm{~V}$ with excellent photoresponse stability. Generally, good reproducibility and baseline stability of the detectors were observed upon repeated exposure and removal of UV light. Hence, the photodetectors were stable and the recovery abilities were maintained after several exposure cycles.

Acknowledgments The authors would like to thank the NanoOptoelectronics Research and Technology Laboratory of the School of Physics at the Universiti Sains Malaysia for the help extended during the research. We are also grateful for the funding provided by the Postgraduate Research Grant Scheme (PRGS) (Grant No. 1001/PFIZIK/845006) of the Universiti Sains Malaysia.

\section{References}

[1] H. Sheng, S. Muthukumar, N.W. Emanetoglu, Y. Lu, Appl. Phys. Lett. 80, 2132 (2002)

[2] K. Ip, Y.W. Heo, K.H. Baik, D.P. Norton, S.J. Pearton, S. Kim, J.R. LaRoche, F. Ren, Appl. Phys. Lett. 84, 2835 (2004)

[3] H.L. Mosbacker, Y.M. Strzhermechny, B.D. White, P.E. Smith, D.C. Look, D.C. Reynolds, C.W. Litton, L.J. Brillson, Appl. Phys. Lett. 87, 012102 (2005)

[4] B. Angadi, H.C. Park, H.W. Choi, J.W. Choi, W.K. Choi, J. Phys. D 40, 1422 (2007)

[5] S.J. Young, S.J. Chang, L.W. Ji, T.H. Meen, C.H. Hsiao, K.W. Liu, K.J. Chen, Z.S. Hu, Microelectron. Eng. 88, 113 (2011)

[6] Y.Z. Li, X.M. Li, X.D. Gao, J. Alloys Compd. 509, 7193 (2011)

[7] C.S. Singh, G. Agarwal, G. Durga Rao, S. Chaudhary, R. Singh, Mater. Sci. Semicond. Process. 14, 1 (2011)

[8] K. Dhananjay, J. Nagaraju, S.B. Krupanidhi, Phys. B 391, 344 (2007)

[9] W. Mtangi, F.D. Auret, C. Nyamhere, P.J. Janse van Rensburg, A. Chawanda, M. Diale, J.M. Nel, W.E. Meyer, Phys. B 404, $4402(2009)$

[10] K. Liu, M. Sakurai, M. Aono, Sens. Actuators B 157, 98 (2011)

[11] O. Lupan, L. Chow, G. Chai, L. Chernyak, O. Lopatiuk, Phys. State Solid A 205, 2673 (2008)

[12] N.H. Al-Hardan, M.J. Abdullah, H. Ahmad, A.A. Aziz, L.Y. Low, Solid State Electron. 55, 59 (2011)

[13] H. Yang, S. Nie, Mater. Chem. Phys. 114, 279 (2009)
[14] S. Dhara, P.K. Giri, Chem. Phys. Lett. 541, 39 (2012)

[15] J. Sun, F. Juan, H. Huang, J. Zhao, Z. Hu, X. Zhang, Y. Wang, Appl. Surf. Sci. 257, 921 (2010)

[16] D.T. Phan, G.S. Chung, Appl. Surf. Sci. 257, 4339 (2011)

[17] R. Elilarassi, G. Chandrasekaran, Mater. Chem. Phys. 121, 378 (2010)

[18] C. Zhang, J. Phys. Chem. Solids 71, 364 (2010)

[19] Y. Hwang, H. Kim, Y. Um, Curr. Appl. Phys. 12, S76 (2012)

[20] V.V. Khomyak, M.M. Slyotov, I.I. Shtepliuk, G.V. Lashkarev, O.M. Slyotov, P.D. Marianchuk, V.V. Kosolovskiy, J. Phys. Chem. Solids 74, 291 (2013)

[21] R. Elilarassi, G. Chandrasekaran, Mater. Sci. Semicond. Process. 14, 179 (2011)

[22] T.Y. Chiang, C.L. Dai, D.M. Lian, J. Alloys Compd. 509, 5623 (2011)

[23] M. Salavati-Niasari, F. Davar, A. Khansari, J. Alloys Compd. 509, 61 (2011)

[24] J.J. Hassan, Z. Hassan, H. Abu-Hassan, J. Alloys Compd. 509, 6711 (2011)

[25] H.S. Al-Salman, M.J. Abdullah, Measurement 46, 1698 (2013)

[26] T. Ghosh, M. Dutta, D. Basak, Mater. Res. Bull. 46, 1039 (2011)

[27] J.W. Hoon, K.Y. Chan, J. Krishnasamy, T.Y. Tou, D. Knipp, Appl. Surf. Sci. 257, 2508 (2011)

[28] S.K. Panda, C. Jacob, Solid State Electron. 73, 44 (2012)

[29] B.Q. Wang, X.D. Shan, Q. Fu, L. Javed, Y. Lv, H.G. Fu, D.P. Yu, Phys. E 41, 413 (2009)

[30] H. Hao, M. Qin, P. Li, J. Alloys Compd. 515, 143 (2012)

[31] S. Ren, G. Fan, S. Qu, Q. Wang, J. Appl. Phys. 110, 084312 (2011)

[32] V.A.L. Roy, A.B. Djurisic, W.K. Chan, J. Gao, H.F. Lui, C. Surya, Appl. Phys. Lett. 83, 141 (2003)

[33] J.P. Borah, K.C. Sarma, Acta Phys. Pol. A 114, 713 (2008)

[34] P. Prepelita, R. Medianu, B. Sbarcea, F. Garoi, M. Filipescu, Appl. Surf. Sci. 256, 1807 (2010)

[35] Ş. Aydoğan, K. Çınar, H. Asıl, C. Coşkun, A. Türüt, J. Alloys Compd. 476, 913 (2009)

[36] T. Han, Y. Shi, H. Wu, C. Liu, Curr. Appl. Phys. 12, 1536 (2012)

[37] W. Mtangi, F.D. Auret, A. Chawanda, P.J. Janse van Rensburg, S.M.M. Coelho, J.M. Nel, M. Diale, L. van Schalkwyk, C. Nyamhere, Mater. Sci. Eng. B 177, 180 (2012)

[38] S.M. Shaban, N.M. Saeed, R.M. Al-Hadad, Ind. J. Sci. Technol. 4, 384 (2011)

[39] X.J. Zheng, Y.Q. Chen, T. Zhang, B. Yang, C.B. Jiang, B. Yuan, Z. Zhu, Sens. Actuators B 147, 442 (2010)

[40] B. Yuan, X.J. Zheng, Y.Q. Chen, B. Yang, T. Zhang, Solid State Electron. 55, 49 (2011)

[41] K.J. Chen, F.Y. Hung, S.J. Chang, S.J. Young, J. Alloys Compd. 479, 674 (2009)

[42] O.M. Berengue, M.K. Kanashiro, A.J. Chiquito, C.J. Dalmaschio, E.R. Leite, Semicond. Sci. Technol. 27, 065021 (2012)

[43] Y. He, W. Zhang, S. Zhang, X. Kang, W. Peng, Y. Xu, Sens. Actuators A 181, 6 (2012)

[44] L. Guo, H. Zhang, D. Zhao, B. Li, Z. Zhang, M. Jiang, D. Shen, Sens. Actuators B 166-167, 12 (2012)

[45] P.Y. Yang, J.L. Wang, W.C. Tsai, S.J. Wang, J.C. Lin, I.C. Lee, C.T. Chang, H.C. Cheng, Thin Solid Films 518, 7328 (2010)

[46] T. Zhai, X. Feng, M. Liao, X. Xu, H. Zeng, B. Yoshio, D. Golberg, Sensors 9, 6504 (2009)

[47] D. Jiang, J. Qin, X. Zhang, Z. Bai, D. Shen, Mater. Sci. Eng. B 176, 736 (2011)

[48] S.S. Shinde, K.Y. Rajpure, Mater. Res. Bull. 46, 1734 (2011)

[49] M. Rajabi, R.S. Dariani, A. Iraji Zad, Sens. Actuators A 180, 11 (2012) 